\section{Assessments of maternal psychosocial adaptation for pre-labor hospitalized pregnant women in Japan}

\author{
Yasuka Nakamura, Toyoko Yoshizawa, \\ Fumi Atogami \\ Women's Health Nursing, Tohoku \\ University Graduate School of Medicine, \\ Japan
}

\section{Abstract}

Maternal psychosocial adaptation to pregnancy is significant task for women during pregnancy. Antepartum hospitalization is often characterized by maternal anxiety, boredom, feelings of imprisonment, and loneliness. The purpose of this study was to explore maternal psychosocial adaptation during pregnancy for hospitalized pregnant women compared with such adaptation in low-risk pregnant women from a reference population. This was a cross-sectional study with convenience samples of high-risk hospitalized and low-risk mothers. This study was carried out in five hospitals and two clinics between March and December 2009 in several areas of Japan. Subjects were 189 hospitalized women diagnosed with premature labor who had received continuous 24 -h treatment with intravenous ritodrine hydrochloride for more than 1 week. The Japanese version of Prenatal Self-Evaluation Questionnaire was administered to measure maternal psychosocial adaptation during pregnancy. Women in hospitalized group had significantly lower adaptation in acceptance of pregnancy and preparation for labor $(\mathrm{P}<.05-.001)$ and showed significantly higher adaptation in identification of a motherhood role and relationship with her husband. Moreover, in hospitalized group, relationship with her husband showed significantly higher adaptation $(\mathrm{P}<.05)$ in primipara, acceptance of pregnancy and preparation for labor were significantly lower adaptation score $(\mathrm{P}<.01-.001)$ in multipara. Hospitalized pre-term pregnant women should be assessed maternal psychosocial adaptation especially the domains of acceptance of pregnancy, preparation for labor, relationship with her husband, and identification of a motherhood role. Health care provider should know the character and background of those women as well as the character of primipara and multipara.

\section{Introduction}

In Japan, medically high-risk pregnancies are increasing because age at childbirth is increasing, and lifestyle and eating habits are changing. In 2007 in Japan, 17\% of all births involved pre-term labor, and $5.0 \%$ of women had pregnancy-induced hypertension. ${ }^{1}$ High risk pregnancies are defined by the Japan Society of Obstetrics and Gynecology as pregnancies with a potential serious prognosis for mother, child, or both during pregnancy or after delivery. ${ }^{2}$ Women with high-risk pregnancies are often hospitalized during pregnancy, treated with bed rest or activity restriction, and given 24-h continuous intravenous treatment with ritodrine hydrochloride. ${ }^{3,4}$ In Japan, this treatment for pre-term labor is accompanied by daily monitoring of uterine contractions and fetal status as well as frequent ultrasound examinations. Most women in Japan who are diagnosed with pre-term labor and needing bed rest are hospitalized. Home care is rare.

Any pregnancy is a period of psychosocial transition in lifestyle ${ }^{5}$ with the preparation for becoming a mother, including accepting a baby into both a woman's self-system and living space. ${ }^{6}$ Moreover, pregnancy is known as a highly stressful event ${ }^{7}$ and is often expected to be a burden as various physical, psychological, and social abilities are needed to adapt to or overcome the physical and mental changes experienced. ${ }^{8}$ Women must adapt to a dramatic shift in lifestyle as they change from an individual responsible primarily for herself to a parent responsible for the life and well-being of a child. ${ }^{9}$ Lederman and Weis ${ }^{5}$ discussed the importance of seven dimensions of psychosocial adaptation to pregnancy including acceptance of pregnancy, identification with a mother role, relationship with mother, relationship with husband or partner, preparation for labor, prenatal fear of pain, helplessness, and loss of control in labor, and prenatal fear of loss of self-esteem in labor. This conceptual model views pregnancy as a period of transition between two lifestyles that can be considered a paradigm shift. A sense of crisis related to pregnancy is felt only when the two paradigms are far apart, when the two lifestyles cannot be reconciled, or when the developmental steps are too large to make in 9 months. As a consequence, almost inevitably the new child cannot be easily integrated into the former paradigm. When the loss of former lifestyle is not counterbalanced by a clear transition to the new lifestyle, a greater level of conflict and anxiety results. Unresolved conflicts and fears during pregnancy can be predictive of fetal new-born health status as well as progress in labor, such as higher plasma epinephrine, lower uterine contractility, longer duration of labor in phase 2 , increased fetal heart rate deceleration during labor, and lower Apgar score. Moreover, pregnancy-specific dimensions of psychological conflict and anxiety can be predictive of length of gestation as well as antepartum and
Correspondence: Yasuka Nakamura, 2-1 Seiryomachi Aobaku Sendai MIYAGI, Japan 9808575.

Tel./Fax: +81.22 .717 .7957$

E-mail: nakamurayasuka@nursing.med.tohoku.ac.jp

Key words: psychosocial adaptation, hospitalization, pregnancy, preterm labor.

Received for publication: 22 August 2011. Revision received: 19 October 2011.

Accepted for publication: 19 October 2011.

This work is licensed under a Creative Commons Attribution NonCommercial 3.0 License (CC BYNC 3.0).

(C) Copyright Y. Nakamura et al., 2011

Licensee PAGEPress, Italy

Nursing Reports 2011; 1:e9

doi:10.4081/nursrep.2011.e9

intrapartum complications. ${ }^{5}$ Lepecka-Klusek and Jakiel ${ }^{10}$ examined the adaptation process in pregnant women who became pregnant as a result of assisted reproductive techniques. Results showed that younger women (up to age 30) living in rural areas who were better educated and lived in better socio-economic conditions had more difficulty adapting to their pregnancy. Chou et al. ${ }^{11}$ reported that $37.6 \%$ of the variance in maternal psychosocial adaptation measured by the Prenatal SelfEvaluation Questionnaire ${ }^{12}$ was explained by severity of nausea and vomiting, perceived stress, social support, and pregnancy planning among Taiwanese pregnant women. Lederman and her colleagues ${ }^{5}$ and other researchers have studied maternal psychosocial adaptation to pregnancy in multiethnic, lower socio-economic, single and or partnered women, as well as those employed and unemployed, teenagers, outpatient or low-risk pregnant women, and pregnant women with symptoms caused by pregnancy.

Hospitalization represents a challenging situation that makes it difficult for pregnant women to integrate the two lifestyles. For most women, being hospitalized is not an expected event in their pregnancy. If hospitalized pregnant women do not adapt well to their pregnancy psychosocially, it may affect their pregnancy progress and fetal health status. Moreover, if the mother-to-be struggles with ambivalence regarding not only her pregnancy but also motherhood, little progress may be made in role clarification in the current or future pregnancies. ${ }^{5}$

Antepartum hospital bed rest is often characterized by maternal anxiety and fear, ${ }^{13-16}$ with women reporting that they experienced a variety of emotions such as boredom, a sense of timelessness, lack of control, uncertainty, a feeling of imprisonment, and loneliness. ${ }^{13-}$ 
$15,17,18$ In Japan, anxiety and stress in hospitalized pregnant women has been studied. Nakazawa et al. ${ }^{19}$ interviewed three hospitalized pregnant women in a maternal-fetal intensive care unit about their anxiety. They identified seven relevant categories including role change as a wife and mother, medical treatment and procedures, thoughts about delivery, and thoughts about their fetus. Tadenuma and Imazeki ${ }^{18}$ explored anxiety in ten hospitalized pregnant women and found they felt anxiousness about the fetus, possible premature delivery, the delivery, the baby, self, and caring for the baby. Pregnant women have to perform certain developmental tasks while making the paradigm shift. Therefore, hospitalized pregnant women should be assessed for Lederman's ${ }^{5}$ seven dimensions of maternal psychosocial adaptation as well as for stress and anxiety. The purpose of this study was to explore maternal psychosocial adaptation during pregnancy in hospitalized pre-term pregnant women compared with such adaptation in low-risk pregnant women from a reference population..$^{20}$ In this study, based on Lederman's theory, maternal psychosocial adaptation was defined as a woman's adaptive challenges expressed by personal conflict and critical resistance that arise in pregnancy when she is transitioning to a new lifestyle.

\section{Materials and Methods}

\section{Subjects and procedure}

A cross-sectional, descriptive comparative study design and two convenience samples of high-risk hospitalized and low-risk pregnant women were used. The high-risk pregnant women were the pre-term pregnant women who were hospitalized were recruited from five hospitals and two clinics between March and December 2009 in the Tohoku (north-east), Kanto (east), and Kansai (west) areas of Japan. Women were eligible for this study if they were able to read and write Japanese and consented to participate. Inclusion criteria for the hospitalized group were i) a diagnosis of threatened premature labor (diagnosed after the $22^{\text {nd }}$ week of pregnancy in Japan) and ii) having received continuous 24-h treatment with intravenous ritodrine hydrochloride for more than 1 week. Women received a questionnaire from a midwife, and if they agreed to participate, they filled in the questionnaire and sealed it for return in a ward collection box. Even if they met the criteria, pregnant women whose fetus was predicted to have a poor prognosis after birth or women who were mentally unstable were excluded by clinical staff. The questionnaire was anonymous. Approval for the study was obtained from the research facility's ethics committee (approval number 2009-73) and the relevant medical facilities.

In addition, based on Okayama and Takahashi ${ }^{20}$, another convenience sample of women in the low-risk pregnancy group were recruited from five outpatient clinics in the Kansai area. Inclusion criteria were women who were Japanese, married, living with a husband, and had no obstetrical abnormalities or complications..$^{20}$

\section{Instruments}

The Prenatal Self-Evaluation Questionnaire, a self-report instrument, was developed by Lederman ${ }^{12}$ and measures seven personal dimensions of psychosocial adaptation to pregnancy based on clinical interviews with pregnant women. After obtaining the developer's permission, the Japanese version of the Prenatal Self-Evaluation Questionnaire (PSEQ) ${ }^{20}$ was administered and carried out by stepping on adequate steps. This 71-item scale measures psychosocial variables relevant to pregnancy and labor using a 4-point Likert scale, scored from 1 (not at all) to 4 (very much so). The possible range of total scores is 71 to 284. Lower scores indicate more positive maternal psychosocial adaptation. The PSEQ has seven dimensions: acceptance of pregnancy; identification of a motherhood role; relationship with mother; relationship with husband; preparation for labor, fear of helplessness and loss of control in labor; and concern for the well-being of self and baby.

In previously reported research, Cronbach's alphas for the original PSEQ in each of the three trimesters of pregnancy among the seven dimensions were .74 to $.91, .71$ to .93 , and .73 to .92 , respectively. ${ }^{12,21}$ Cronbach's alphas for the seven subscales ranged from .76 to .87 . Predictive validity for the instrument has been confirmed by its relations with anxiety during labor and postpartum psychosocial adaptation. ${ }^{12}$ For the Japanese version of the PSEQ, Cronbach's alpha for the seven dimensions ranged from .75 to $.85 .{ }^{20}$ For criterionrelated validity, the Japanese version of the PSEQ was correlated with the State-Trait Anxiety Inventory (STAI), a well-known anxiety measure. ${ }^{20}$ The reliability coefficient for the PSEQ using Cronbach's alpha was .93, ranging from .78 to .89 among the seven dimensions in this study.

Socio-demographic and obstetrical characteristics such as age, partner's age, education level, marital status, family type, employment, gestational week, number of fetuses, days of hospitalization, and level of activity in the hospital were collected from simple questionnaires.

\section{Statistical analyses}

SPSS version $17.0 \mathrm{~J}$ was used for data analy- sis. Sociodemographic and clinical data were compared between the hospitalized group and a low-risk pregnancy group ${ }^{20}$ using analysis of t-tests or the Wilcoxon rank-sum test depending on whether the group's distribution followed the normal curve. The level of significance was $\mathrm{P}<.05$.

\section{Results}

The questionnaire was distributed to 246 hospitalized pregnant women. After exclusions (for example, those hospitalized less than one week), 189 subjects were included in the analysis (valid response rate of returned questionnaires was $85.5 \%$ ). $0 n$ the other hand, 405 low-risk outpatient pregnant women received questionnaire, and 188 primipara and 142 multipara were included criteria (valid response rate returned questionnaire was 81.5\%). Of those low-risk women, 163 primiparas and 118 multiparas in the $2^{\text {nd }}$ trimester or the $3^{\text {rd }}$ trimester were selected in the analysis ${ }^{20}$, because the hospitalized pregnant women were also either in the $2^{\text {nd }}$ or the $3^{\text {rd }}$ trimester.

\section{Characteristics of patients}

Table 1 shows the demographic characteristics of the hospitalized mother group. The mean age ( \pm SD) of all subjects and their husbands was $31.4( \pm 4.7)$ years and $33.0( \pm 5.2)$ years, respectively. Most patients had completed a post-high school education. Half were junior college or specialized school graduates, and about a quarter were university graduates. Over $95 \%$ were married, and about half were employed. Activity restrictions included bathing and toilet limitations as well as activity range. Although a quarter of them could take a shower every day, most of them could only take a shower once every few days.

In the low-risk pregnancy reference group, ${ }^{20}$ all the women were married and mean age $( \pm$ SD) was $27.1( \pm 3.7)$ for primiparas and 30.0 $( \pm 3.4)$ for multiparas. Compared to the hospitalized group, both primiparas and multiparas in the low-risk pregnancy group were significantly younger.

\section{Prenatal self-evaluation question- naire score}

Figure 1 shows the PSEQ scores for hospitalized women and reference scores for lowrisk pregnant women in Japan. The hospitalized women had significantly lower adaptation scores for acceptance of pregnancy and preparation for labor compared to low-risk pregnant women $(\mathrm{Z}=2.09, \mathrm{P}<.051$, Effect size: $\mathrm{d}=0.199$, $1-\beta=0.533 ; Z=3.69, P<.001$, Effect size: $d=$ $0.199,1-\beta=0.537$, respectively). Scores for identification of a motherhood role and rela- 
tionship with husband indicated significantly higher adaptation in hospitalized pre-term pregnant women than that in low-risk pregnant women $(Z=2.10, P<.05$, Effect size: $d=$ $0.221,1-\beta=0.626 ; \mathrm{Z}=2.31, \mathrm{P}<.05$, Effect size: $\mathrm{d}=0.353,1-\beta=0.954$, respectively).

It has previously been shown that maternal psychosocial adaptation is different between primiparas and multiparas.,22 Therefore, in this study, primiparas and multiparas were compared in each population.

In primiparas, there were significantly higher adaptation scores for relationship with husband in hospitalized pre-term pregnant women compared to low-risk pregnant women $(\mathrm{Z}=2.19$, $P<.05$, Effect size: $d=0.271,1-\beta=0.572)$. On the other hand, in hospitalized pre-term multiparas, there were significantly lower adaptation scores for acceptance of pregnancy and preparation for labor compared to low-risk pregnant women $(\mathrm{Z}=3.04, \mathrm{P}<.01$, Effect size: $\mathrm{d}=0.442,1$ $\beta=0.831 ; Z=3.34, P<.001$, Effect size: $d=0.500$, $1-\beta=0.909$, respectively) (Table 2$)$.

\section{Discussion}

The mean age of hospitalized pregnant women in this study was 31.4 years, slightly older than the average 30.3 years of Japanese women giving birth in 2008. ${ }^{23}$ Subjects had a comparatively good academic background, with $75.6 \%$ having more than 12 years of education compared with $55.3 \%$ of Japanese women in $2009 .{ }^{24}$ This difference was possibly related to the slightly older age of the women in the study. The rate of married women in this study, which was over $95 \%$, is unusual compared to other countries, but is typical in Japan. In Japan, the proportion of illegitimate births to total live births was $2.1 \%$ in 2009 , an incredibly low number. ${ }^{25}$

Hospitalized pre-term pregnant women who were primiparas had higher adaptation scores for relationship with husband than did the lowrisk pregnant reference group. ${ }^{20}$ Items in relationship with husband deal with mutuality, support, and communication patterns in the marital relationship (for example, my husband is interested in discussing the pregnancy with me). ${ }^{12}$ Primiparas may have had lower scores because husbands' worry and support for their hospitalized wives could be seen at delivery or when husbands visited the hospital.

In addition, because hospitalized primiparas were significantly older than low-risk primiparas, they may have had a more mature relationship with their husband. It is also possible that marriage duration might be related to the relationship with husband, but it was not collected as data in this study.

Shinkawa ${ }^{26}$ explored first fathers' responses to expectant wives being hospitalized for

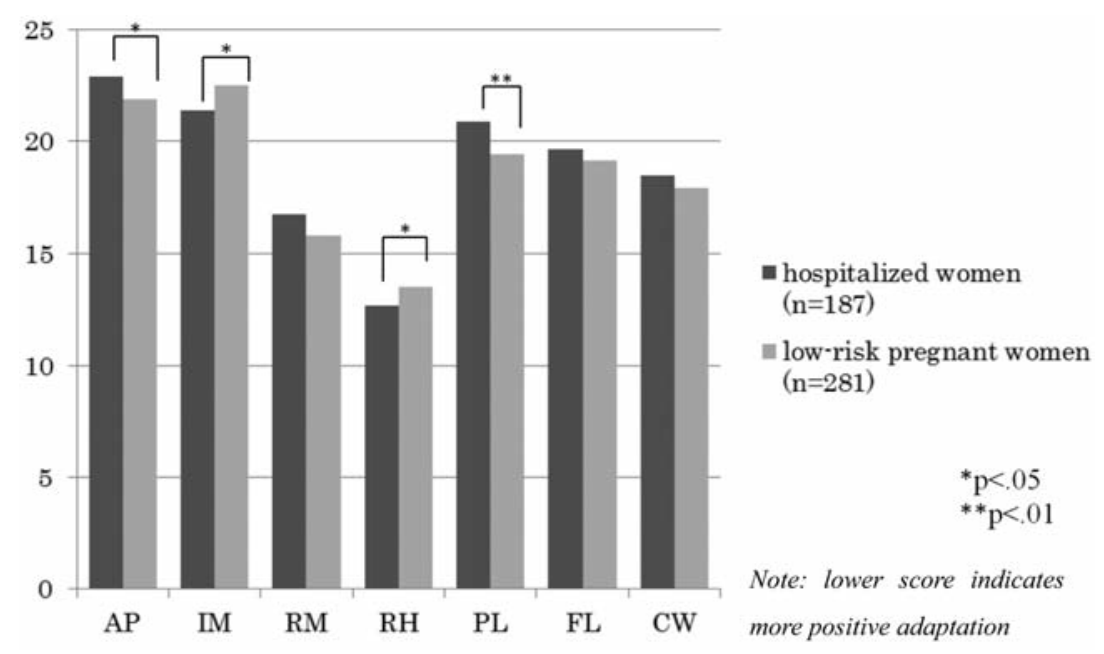

Figure 1. Scores of the seven sub-scales of the Prenatal Self-Evaluation Questionnaire. $A P$, acceptance of pregnancy; $I M$, identification of a motherhood role; $R M$, relationship with her mother; $R H$, relationship with her husband; $P L$, preparation for labor; $F L$, fear of helplessness and loss of control in labor; $C W$, concern for the well-being of self and baby.

Table 1. Demographic characteristics.

\begin{tabular}{|c|c|c|c|}
\hline & $\begin{array}{l}\text { Hospitalized } \\
\text { Group }(n=189)\end{array}$ & $\begin{array}{c}\text { Primipara } \\
(n=111)\end{array}$ & $\begin{array}{c}\text { Multipara } \\
(n=78)\end{array}$ \\
\hline Age, y mean (SD) & $31.4(4.7)$ & $30.1(4.4)$ & $33.1(4.4)$ \\
\hline Husbands' age, y mean (SD) & $33.0(5.2)$ & $31.9(4.5)$ & $34.6(5.7)$ \\
\hline $\begin{array}{l}\text { Education level } \\
\text { Junior high school } \\
\text { High school } \\
\text { Junior college / special school } \\
\text { University / College } \\
\text { Graduate school }\end{array}$ & $\begin{array}{c}5(2.6 \%) \\
40(21.2 \%) \\
94(49.7 \%) \\
48(25.4 \%) \\
1(0.5 \%)\end{array}$ & $\begin{aligned} & 3(2.7 \%) \\
& 24(21.6 \%) \\
& 53(47.7 \%) \\
& 31(27.9 \%) \\
& 0(0 \%)\end{aligned}$ & $\begin{array}{c}2(2.5 \%) \\
16(20.5 \%) \\
41(52.6 \%) \\
17(21.8 \%) \\
1(1.3 \%)\end{array}$ \\
\hline $\begin{array}{l}\text { Occupation } \\
\text { Employed } \\
\text { Unemployed }\end{array}$ & $\begin{array}{l}93(49.2 \%) \\
94(49.7 \%)\end{array}$ & $\begin{array}{l}57(51.4 \%) \\
52(46.8 \%)\end{array}$ & $\begin{array}{l}36(46.2 \%) \\
42(53.8 \%)\end{array}$ \\
\hline $\begin{array}{l}\text { Marriage status } \\
\text { Married } \\
\text { Planning marriage } \\
\text { Unmarried }\end{array}$ & $\begin{array}{l}183(96.8 \%) \\
2(1.1 \%) \\
2(1.1 \%)\end{array}$ & $\begin{array}{c}106(95.5 \%) \\
1(0.9 \%) \\
2(1.8 \%)\end{array}$ & $\begin{array}{l}77(98.7 \%) \\
1(1.3 \%) \\
0(0 \%)\end{array}$ \\
\hline $\begin{array}{l}\text { Family type } \\
\text { Nuclear } \\
\text { Expanded }\end{array}$ & $\begin{array}{r}158(83.6 \%) \\
28(14.8 \%)\end{array}$ & $\begin{array}{l}94(84.7 \%) \\
14(12.6 \%)\end{array}$ & $\begin{array}{l}64(82.1 \%) \\
14(17.9 \%)\end{array}$ \\
\hline $\begin{array}{l}\text { Pregnancy desire } \\
\text { planned } \\
\text { wanted but unplanned } \\
\text { wanted but not now } \\
\text { unexpected }\end{array}$ & $\begin{array}{l}71(37.6 \%) \\
67(35.4 \%) \\
35(18.5 \%) \\
15(7.9 \%)\end{array}$ & $\begin{array}{c}42(37.8 \%) \\
45(40.5 \%) \\
19(17.1 \%) \\
5(4.5 \%)\end{array}$ & $\begin{array}{l}29(37.2 \%) \\
22(28.2 \%) \\
16(20.5 \%) \\
10(12.8 \%)\end{array}$ \\
\hline $\begin{array}{l}\text { Gestational weeks, mean (SD, range) } \\
36 \text { ) }\end{array}$ & $30.6(4.4,22-37)$ & $30.6(4.7,22-37)$ & $30.0(4.2,24-$ \\
\hline $\begin{array}{l}\text { Hospitalized day, mean (SD) } \\
\text { Singleton fetus } \\
\text { Twins } \\
\text { Triplets }\end{array}$ & $\begin{array}{l}18.7(14.7) \\
168(88.9 \%) \\
20(10.6 \%) \\
1(0.5 \%)\end{array}$ & $\begin{aligned} 17.6 & (13.4) \\
93 & (83.8 \%) \\
15 & (19.2 \%) \\
0 & (0 \%)\end{aligned}$ & $\begin{array}{c}20.0(16.1) \\
70(89.7 \%) \\
5(6.4 \%) \\
1(1.3 \%)\end{array}$ \\
\hline $\begin{array}{l}\text { Bed rest level } \\
\text { Shower everyday }\end{array}$ & $46(24.3 \%)$ & $21(26.9 \%)$ & $25(32.1 \%)$ \\
\hline $\begin{array}{l}\text { Level of clean caring } \\
\text { Shower once in a few days } \\
\text { Bed bath } \\
\text { Bedridden } \\
\text { Can walk }\end{array}$ & $\begin{aligned} & 120(63.5 \%) \\
& 20(10.8 \%) \\
& 2(1.1 \%) \\
& 184(97.4 \%)\end{aligned}$ & $\begin{array}{c}76(68.5 \%) \\
12(10.8 \%) \\
1(0.9 \%) \\
109(98.2 \%)\end{array}$ & $\begin{aligned} 44 & (56.4 \%) \\
6 & (10.3 \%) \\
1 & (1.3 \%) \\
75 & (96.2 \%)\end{aligned}$ \\
\hline $\begin{array}{l}\text { Way to toilet } \\
\text { Bedside } \\
\text { Insertion toilet } \\
\text { Indwelling bladder catheter } \\
\text { Free in a ward }\end{array}$ & $\begin{array}{c}4(2.1 \%) \\
0(0.0 \%) \\
1(0.5 \%) \\
76(40.2 \%)\end{array}$ & $\begin{array}{l}2(1.8 \%) \\
0(0.0 \%) \\
0(0.5 \%) \\
42(37.8 \%)\end{array}$ & $\begin{array}{c}2(2.6 \%) \\
0(0.0 \%) \\
1(1.3 \%) \\
34(43.6 \%)\end{array}$ \\
\hline $\begin{array}{l}\text { Activity range } \\
\text { Only in a room and toilet } \\
\text { Only bedside } \\
\text { Only on a bed } \\
\end{array}$ & $\begin{array}{c}107(56.6 \%) \\
2(1.1 \%) \\
3(1.6 \%)\end{array}$ & $\begin{array}{l}67(60.4 \%) \\
1(0.9 \%) \\
0(0 \%)\end{array}$ & $\begin{array}{c}40(51.3 \%) \\
1(1.3 \%) \\
3(3.8 \%)\end{array}$ \\
\hline
\end{tabular}


threatened premature delivery. All subjects had a strong awareness of having a child and becoming a father. For those men, the child was thought about more frequently in daily life because of the awareness that the child might be born at any time. In contrast, Wakita et al. ${ }^{27}$ reported that the perceived amount of support from husbands of multiparas was significantly less than during previous pregnancies. Moreover, Wakita et al. ${ }^{28}$ reported that the amount of intimacy with their husband during late pregnancy for multiparas was significantly lower than that for primiparas. Although subjects in that study were outpatient pregnant women, similar findings regarding expectant fathers whose wives are hospitalized might be expected. A possible reason for less intimacy between a husband and his hospitalized wife is related to family structure. Perhaps husbands of primiparas have more time to come and visit their wives than husbands of multiparas who have to take care of children at home, although there are no data to support this premise. Because feelings are often inferred from observable attitudes in the Japanese culture, ${ }^{29}$ a husband's compassion and anxiety may not be seen, but instead is assumed from attitudes and behaviors such as bringing food or presents to the hospital.

Hospitalized pre-term pregnant women who were multiparas had lower adaptation scores for acceptance of pregnancy and preparation for labor than the low-risk pregnant reference group..$^{20}$ The Acceptance of pregnancy items are focused on the gravidas' responses specifically to their pregnancy such as her enjoyment of pregnancy, tolerance of discomfort and extent of ambivalence, rather than their general psychological reactions. ${ }^{12}$ Attitudes toward pregnancy are assumed to be influenced by their distress resulting from 24-h continuous intravenous treatment and the discomfort due to their hospital life, as well as their desire for this pregnancy to be like the previous pregnancy. According to research investigating how hospitalized pregnant women respond to pregnancy, the women characterized their pregnancy as stressful due to the unexpected progress of the pregnancy and pregnancy of somebody else's problem. ${ }^{30}$ Perhaps because hospitalized multiparas compared this pregnancy with previous pregnancies that did not require hospitalization or were without major problems, they had difficulty dealing with this high-risk pregnancy positively. The health condition of pregnant women and their relationship with their children influence their acceptance of pregnancy. ${ }^{31}$ Ohinata ${ }^{32}$ reported that a change in attitude toward pregnancy is influenced by difficulties related to daily life. Viewing the pregnancy positively and accepting it are the important factors in the psychological and physical preparation for delivery and childbearing, which serve for advancing the parental role. ${ }^{31}$ This supports the results of this study showing that hospitalized pre-term pregnant multiparas had lower adaptation scores for Preparation for Labor and Acceptance of Pregnancy. The Preparation for Labor dimension assesses the extent to which the gravidas feel informed and prepared to cope with the labor event. Because multiparas already knew how to cope with labor, they concentrated on other things, such as continuing this pregnancy and adjusting relationships with their children.

Interestingly, in total, hospitalized pregnant women had significantly higher adaptation scores for identification of a motherhood role than low-risk pregnant women, possibly because they had more time to reflect on their situation. Many studies examining the experiences of high-risk pregnant women on bed rest have reported that these women experience boredom. ${ }^{33-35}$ However, they get daily information concerning their fetus from fetal heart rate monitoring and ultrasound examinations, and they have many opportunities to meet mothers and newborn babies in the hospital. Nakamura $^{36}$ reported that hospitalized pregnant women feel that frequent ultrasound examinations and fetal heart rate monitoring everyday are positive experiences, providing evidence that their fetus is healthy. In addition, hospitalized pregnant women appreciate having friends who are in the same situation and with whom they can exchange information not only during their present pregnancy, but also after delivery and when their child enters nursery school. ${ }^{36}$

\section{Nursing implications}

In this study, results showed that hospitalized pre-term pregnant women's maternal psychosocial adaptation, particularly in relation to the acceptance of pregnancy, preparation for labor, relationship with husband, and identification of a motherhood role, differed from lowrisk pregnant women's maternal psychosocial adaptation. This study contributes to understanding hospitalized pregnant women as well as the needs and interventions specific to these women. Findings can help primary care providers, such as midwives, nurses, and doctors, improve the quality of care, plan childbirth education for hospitalized pregnant women, and perform nursing interventions, thereby reducing maternal stress and promoting adaptation to pregnancy.

Even if pregnant women are not hospitalized, they need prenatal education that includes challenges common to primiparas and multiparas. Results of this study showing that hospitalized pregnant women had a higher adaptation for identification of a motherhood role than low-risk pregnant women indicates there are advantages to women being hospitalized during ante-partum. For example, women can meet others in the same situation, have an opportunity to see newborn babies, and talk with new mothers. Furthermore, women in the hospital can quickly address questions about their pregnancy with health care providers. Care providers should pay attention to these advantages and as a result provide better care for hospitalized women. For example, planning prenatal education specifically for hospitalized pre-term pregnant

Table 2. Scores for the seven sub-scales of the prenatal self-evaluation questionnaire.

\begin{tabular}{|c|c|c|c|c|c|c|}
\hline n & $\begin{array}{l}\text { Total met } \\
\text { Hospitalized } \\
\text { women } \\
189\end{array}$ & $\begin{array}{l}\text { Low-risk } \\
\text { pregnant } \\
\text { women } \\
281\end{array}$ & $\begin{array}{l}\text { Primipara n } \\
\text { Hospitalized } \\
\text { women } \\
111\end{array}$ & $\begin{array}{l}\text { mean(SD) } \\
\text { Low-risk } \\
\text { pregnant } \\
\text { women } \\
163\end{array}$ & $\begin{array}{c}\text { Multipara II } \\
\text { Hospitalized } \\
\text { women } \\
78\end{array}$ & $\begin{array}{l}\text { mean(SD) } \\
\text { d Low-risk } \\
\text { pregnant } \\
\text { women } \\
118\end{array}$ \\
\hline $\begin{array}{l}\text { Acceptance } \\
\text { of pregnancy }\end{array}$ & $2 2 . 9 \longdiv { ( 5 . 2 ) }$ & $21.9(5.1)$ & $21.9(5.3)$ & $21.6(5.0)$ & $2 4 . 4 \longdiv { ( 4 . 6 ) } *$ & * $* 2.3(5.2)$ \\
\hline $\begin{array}{l}\text { Identification of a } \\
\text { motherhood role }\end{array}$ & $2 1 . 4 \longdiv { 5 . 6 ) }$ & $22.5(5.5)$ & $21.2(5.7)$ & $22.3(5.7)$ & $21.7(5.3)$ & $22.8(5.3)$ \\
\hline $\begin{array}{l}\text { Relationship with } \\
\text { her mother }\end{array}$ & $16.8(5.6)$ & $15.8(4.8)$ & $16.1(5.3)$ & $15.5(4.5)$ & $17.6(5.9)$ & $16.1(5.1)$ \\
\hline $\begin{array}{l}\text { Relationship with } \\
\text { her husband }\end{array}$ & $12.6(4.2)$ & $13.5(3.7)$ & $1 1 . 6 \longdiv { ( 3 . 7 ) }$ & $12.6(3.5)$ & $14.1(4.4)$ & $14.5(3.8)$ \\
\hline $\begin{array}{l}\text { Preparation } \\
\text { for labor }\end{array}$ & $20.9 \widehat{(4.4)}^{*}$ & $* \overline{19.4}(3.9)$ & 21.8 (4.3) & $21.3(4.0)$ & $19.6 \overline{(4.4)}^{*}$ & $* \pi$ \\
\hline $\begin{array}{l}\text { Fear of helplessness } \\
\text { and loss of control } \\
\text { in labor }\end{array}$ & 19.7 (4.3) & $19.2(4.3)$ & 20.5 (4.3) & $20.3(4.5)$ & $18.5(4.1)$ & $18.1(4.2)$ \\
\hline $\begin{array}{l}\text { Concern for the } \\
\text { well-being of self } \\
\text { and baby }\end{array}$ & $18.5(4.9)$ & $17.9(5.5)$ & $18.7(4.5)$ & $18.9(6.5)$ & $18.1(5.4)$ & $17.0(4.5)$ \\
\hline
\end{tabular}

${ }^{*} \mathrm{P}<.05 ; * * \mathrm{P}<.01$ 
women, creating peer support groups, and providing a place where pregnant women can talk about their pregnancies freely would be of value. Hospitalized multiparas had a lower adaptation for acceptance of pregnancy than did low-risk pregnant women. Acceptance of pregnancy is the initial task for pregnant women. Therefore, care providers should take time to talk to women about their pregnancy as well as address their stress or anxiety.

\section{Limitations of this study}

In the convenience sample used for hospitalized women in this study, the women were highly educated and slightly older than the average pregnant patient in Japan and may not have been representative of the Japanese population. Furthermore, this study did not investigate social support and family support factors. In addition, level of activity restriction and nursing care could differ among hospitals, with the size of the facilities having a bearing on this. Further study concerning these factors is warranted.

\section{Conclusions}

Hospitalized pre-term pregnant women should be assessed regarding maternal psychosocial adaptation. Our findings showed that these women felt less adapted regarding acceptance of pregnancy and preparation for labor and more adapted regarding relationship with husband and identification of a motherhood role compared to low-risk pregnant women. Furthermore, maternal psychosocial adaptation differed between primiparas and multiparas. Health care providers should know not only their patients' background, but also characteristics common to these women. In addition, they should know the characteristics of primiparas and multiparas. Although prelabor pregnant women are provided hospitalization and activity restriction as treatment, improved quality of care for those women will help them better adapt to their new motherhood role.

\section{References}

1. Nakabayashi M. High-risk pregnancy: recent trend. Rinshou Fujinka Sanka 2010;64:136771.

2. Japan Society of Obstetrics and Gynecology editor. Sankafujinkayougo-shuu. $2^{\text {nd }}$ ed. Tokyo: Kaneharashuppan; 2008.

3. Japan Society of Obstetrics and Gynecolo-gy editor. sanfujinka shinryo gaidorain; sannkahen 2011. Tokyo: Japan Society of Obstetrics and Gynecology; 2011.

4. Maloni JA. Antepartum bed rest for pregnan- cy complications: efficacy and safety for preventing preterm birth. Biol Res Nurs 2010;12:106-24.

5. Lederman R, Weis K. Psychosocial Adaptation to Pregnancy Seven Dimen-sions of Maternal Development. $3^{\text {rd }}$ ed. New York: Springer; 2009.

6. Rubin R. Maternal Identity and the Maternal Experience. New York: Springer; 1984.

7. Geller P. Pregnancy as a stressful life event. CNS Spectr 2004;9:188-97.

8. Shindo S, Wada S. Bosei no shinrishakaiteki sokumen to kango kea. Tokyo: Igakushoin; 1992.

9. Klaus M, Kennel J, Klaus P. Bonding: Building the foundations of secure attachment and independence. Cambridge, MA: Perseus Books; 1995.

10. Lepecka-Klusek C, Jakiel G. The socio-economic conditioning of difficulties in adaptation to pregnancy following assisted reproductive techniques. Eur J Obstet Gynecol Reprod Biol 2009;143:50-4.

11. Chou FH, Avant KC, Kuo SH, Fetzer SJ. Relationships between nausea and vomiting, perceived stress, social support, pregnancy planning, and psychosocial adaptation in a sample of mothers: A questionnaire survey. Int J Nurs Stud 2008;45:1185-91.

12. Lederman R. Psychosocial Adaptation in Pregnancy Assessment of Seven Dimen-sions of Maternal Development. $2^{\text {nd }}$ ed. New York: Springer; 1996.

13. Heaman M. Stressful life events, social support, and mood disturbance in hospitalized and non-hospitalized women with pregnancyinduced hypertension. Can J Nurs Res 1992;24:23-37.

14. Gupton A, Heaman M, Ashcroft T. Bed rest from the perspective of the high-risk pregnant woman. J Obstet Gynecol Neonatal Nurs 1997;26:423-30.

15. Natori H, Shimada K. Experiences of women undergoing prolonged admissions for highrisk pregnancies, and their meanings. $\mathrm{J}$ Tsuruma Health Sci Soc Kanazawa Univ 2007;30:169-77.

16. Thornburg P. "Waiting" as experienced by women hospitalized during the antepartum period. MCN Am J Matern Child Nurs 2002;27:245-8.

17. Maloni JA, Margevicius SP, Damato EG. Multiple gestation: side effects of antepartum bed rest. Biol Res Nurs 2006;8:115-28.

18. Tadenuma Y, Imazeki S. Anticipatory anxiety in expectant mothers hospitalized for threatened premature delivery. Jpn J Matern Health 2005;46:267-74.

19. Nakazawa E, Abe M, Matsuki Y, et al. Seppakusouzan de MFICU ni chouki nyuuin wo hituyou to suru ninpu no fuan ninpu no mensetu kara. Kagawa Bosei eisei zasshi 2008;8:50-6.

20. Okayama H, Takahashi M. Developing the
Japanese version of the Prenatal SelfEvaluation Questionnaire. J Jpn Soc Psychol Obstet Gynecol 2002;7:55-63.

21. Kiehl EM, White MA. Maternal adaptation during childbearing in Norway, Sweden and the United States. Scand J Caring Sci 2003;17:96-103.

22. Lin CT, Chou FH. [A comparison of maternal psychosocial adaptation among pregnant women with different gravidity]. Hu Li Za Zhi 2008;55:28-36.

23. National Institute of Population and Social Security Research. Population Statistics of Japan 2010. Tokyo; 2010.

24. Gender Equality Bureau Cabinet Office. danjo kyoudou sankaku hakusho. Tokyo; 2010.

25. Ministry of Health Labour and Welfare ed. Outline of vital statistics 2010. Ministry of Health Labour and Welfare; 2010.

26. Shinkawa $\mathrm{H}$. Changes in fathers emotional responses toward pregnancy and birth when expectant wives are hospitalized for threatened prematuer delivery: from hospitalization to delivery. J Jpn Acad Midwif 2006;20:64-73.

27. Wakita M, Kojima Y, Irisawa M. Influence that pregnancy and birth: mother's physical and psycological health value and degree of intimacy with husband. Japan Society of Developmental Pshychology, 10th taikai happyou ronbunshu; 1999. p.396.

28. Wakita M, Kojima Y, Irisawa M. Influence second child's pregnancy and birth to family's psychology and behavior. Jpn J Matern Health 2003;44:244-9.

29. Haga Y. Nihonjinrashisa no Kouzou. Tokyo: Daishukanshoten; 2004.

30. Nakamura Y, Atogami F, Takeuchi M, Yoshizawa T. The attitude of pregnancy under hospitalization of a threatened premature delivery pregnant woman. Jpn J Matern Health 2011:52:197.

31. Ishii K, Ohira M. Psychosocial Character for pregnant women. In: Mori E, editor. Boseikangogaku kakuron. Tokyo: Igakushoin; 2008. p. 55-62.

32. Ohinata M. Bosei no kenkyuu: Sono keisei to Henyou no katei - Dentouteki boseikan heno hanshou. Tokyo: Kawashima Shoten; 1988.

33. Heaman M, Gupton A. Perceptions of bed rest by women with high-risk pregnancies: A comparison between home and hospital. Birth 1998;25:252-8.

34. Maloni JA, Cohen AW, Kane JH. Prescription of activity restriction to treat high-risk pregnancies. J Womens Health 1998;7:351-8.

35. Richter MS, Parkes C, Chaw-Kant J. Listening to the voices of hospitalized high-risk antepartum patient. J Obstet Gynecol Neonatal Nurs 2007;36:313-8.

36. Nakamura Y. Psychosocial Adaptation status and positive experiences for bed-rest pregnant women. 2008-2009 Reports of Grants-inAid for Scientific Research for Young Scientists (B): 2010. 